\title{
ANALYSIS OF THE FIRST CLEAVAGE DIVISION TO DETERMINE THE SEX-RATIO AND INCIDENCE OF CHROMOSOME ANOMALIES AT CONCEPTION IN THE MOUSE
}

\author{
M. H. KAUFMAN \\ Physiological Laboratory, Cambridge CB2 3EG
}

(Received 7th September 1972)

\begin{abstract}
Summary. Fertilized mouse eggs were examined between 27 and $34 \mathrm{hr}$ after superovulation and mating. Out of 1334 eggs examined, 432 were already at the two-cell stage. Of the one-cell eggs, 135 were at metaphase of the first cleavage division with 40 clearly distinguishable chromosomes, and it was possible to sex 123 of these preparations. Sixty-two were found to be male and sixty-one female, corresponding to a sex-ratio at conception of approximately $1: 1$. A moderate incidence of triploidy $(4 \cdot 1 \%)$ and aneuploidy $(8.3 \%)$ was also observed at this stage and one example of hyperdiploidy, an embryo with 41 chromosomes (mouse $2 n=40$ ). A method for distinguishing between all the autosomes and the sex chromosomes at the first cleavage metaphase is described.
\end{abstract}

\section{INTRODUCTION}

Since the publication of a description of an air-drying technique for producing chromosome preparations from mouse eggs (Tarkowski, 1966), there has been a renewed interest in the value of the primary sex-ratio. Possible effects on the sex-ratio of external factors such as seasonal variation or population density can only be studied when the primary sex-ratio of a species is established. The criteria which Stich \& Hsu (1960) applied to somatic cells of the mouse to identify male and female cells were utilized by Vickers (1967) to estimate the sex-ratio from air-dried preparations of mouse blastocysts. This was the earliest developmental stage at which a direct estimation of the sex-ratio had been reported. Chromosomal preparations from later embryos (Ford \& Woollam, 1963) allowed an estimate of the sex-ratio later in gestation (Vickers, 1969a). Indirect approaches to this problem such as the estimate of the sexratio from mouse litters with no apparent prenatal mortality (MacDowell \& Lord, 1925) are open to criticism mainly on the grounds that these litters may not be representative of the whole population, and that it would be very difficult to exclude the possibility of preimplantation loss.

Recent analysis of the first cleavage division (McGaughey \& Chang, 1969, 1971; Donahue, 1972a, b; Kaufman, 1973a, b) has demonstrated the accessibility of this stage for study but it has not been possible to identify the individual 
chromosomes of the first cleavage division in the mouse with the precision and detail possible for the chromosomes of adult mouse tissues (Francke \& Nesbitt, 1971; Miller \& co-authors, 1971; Buckland, Evans \& Sumner, 1971; Schnedl, 1971).

The first cleavage metaphase has the advantage over subsequent mitoses that at this stage there is a greater variation in size between the longest and shortest chromosomes than is apparent in later divisions. This allows sexing to be carried out by the criteria of Stich \& Hsu (1960).

The present investigation was undertaken to determine the sex-ratio in the mouse at conception and to make observations on the incidence of chromosomal anomalies at the first cleavage division. A specific staining procedure was devised which enabled a distinction to be drawn between all the autosomes present at this metaphase; results confirm the validity of sexing cells by the method of Stich \& Hsu (1960).

\section{MATERIALS AND METHODS}

Fifty, female CFLP strain mice (Carworth, Europe), from 8 to 10 weeks old, were induced to superovulate with 10 i.u. PMSG followed at a 48-hr interval by 10 i.u. HCG, and were paired with fertile CFLP males shortly after the HCG injection. Females that had mated were killed between 27 and $34 \mathrm{hr}$ after the HCG injection, and the eggs were flushed from the oviducts.

Air-dried chromosome preparations were made by the method described by Tarkowski (1966) and stained with $2 \%$ Giemsa (Giemsa stain R.66, G. T. Gurr) at $\mathrm{pH} 7.0$ for $1 \mathrm{hr}$. Slides were then dehydrated and mounted with Glearmount (E. Gurr, Ltd). Eggs at the analysable stages of metaphase were examined in detail. All groups where 40 chromosomes could clearly be seen were photographed at $\times 1250$ magnification under oil-immersion and phasecontrast. This usually required three to six photographs to cover the field of the metaphase plate. Composite photographs were then subjected to analysis by two independent observers in order to determine, where possible, the sex of the metaphase group. Karyotyping along the lines described by Stich \& Hsu (1960) for somatic cells was possible in the majority of these preparations.

Groups were sexed according to the number of small chromosomes present, whether a pair (female) or three small chromosomes (male). When there were more than three chromosomes in the smallest group, it was necessary to determine whether there was an odd (male) or even (female) number present. The composite photographs were cut up in the more complex groups to aid pairing of the chromosomes. Pairing was based on size alone, as the staining technique did not allow a more accurate identification of autosomes.

Various pretreatment procedures were investigated which enable the observer to distinguish between autosomes in adult mouse mitoses. Banding was obtained by all these means but was very difficult to analyse.

The method finally adopted was as follows: slides of air-dried chromosome preparations were fixed in ethanol and acetic acid (3:1) and treated within a few hours of fixation with a saturated aqueous solution of barium hydroxide for $10 \mathrm{~min}$. Following the hydroxide treatment, slides were incubated for $1 \mathrm{hr}$ 
at $60^{\circ} \mathrm{C}$ in ' $2 \times \mathrm{SSC}$ ' $(0.3 \mathrm{M}$-sodium chloride plus $0.03 \mathrm{~m}$-trisodium citrate, Buckland et al., 1971) and were then rinsed thoroughly in distilled water and stained with $2 \%$ Giemsa for $20 \mathrm{~min}$. The slides were then rinsed briefly in distilled water, thoroughly air-dried, dehydrated with xylene, and mounted with Clearmount. The most reliable results were obtained when a freshly prepared, unfiltered, aqueous solution of barium hydroxide was used.

This pretreatment technique produced consistent banding patterns characteristic for each chromosome. In control preparations treated with ' $2 \times \mathrm{SSC}$ ' but not with barium hydroxide, chromosomes stained inconsistently, a few showing fine banding while the majority stained uniformly with Giemsa.

\section{RESULTS}

A total of 193 cells was obtained at metaphase of the first cleavage mitosis (see Table 1); 168 of these were diploid; eight cells were triploid; five had 60 chromosomes, and four of these appeared to be XXX in constitution, while the fifth could not be assessed. The sixth group had 58 apparently normal chromosomes with two very small chromosomes, while the remaining two groups had 58 chromosomes. Sixteen cells were hypodiploid, eight of these metaphases having

Table 1. Analysis of metaphase groups from first cleavage mitosis in mice

\begin{tabular}{l|c}
\hline Total number of metaphases & 193 \\
Diploid groups with 40 chromosomes & 168 \\
Total & $135^{*}$ \\
With minimal or no overlapping & 33 \\
With moderate/considerable overlapping & 16 \\
Diploid groups with less than 40 chromosomes & 8 \\
$(8 \times 39,4 \times 38,4$ less than 37$)$ & 1 \\
Triploid groups & \\
Diploid with 41 chromosomes & \\
\hline
\end{tabular}

In 113 groups, there was agreement by two independent observers without consultation; in ten groups, there was agreement after reassessment and consultation by both observers.

* Of these 135 diploid metaphases, sexing was possible in 123 cases.

39 chromosomes. While this finding may be a guide to the incidence of aneuploidy, chromosome losses can be due to technical mishaps, and these groups were not examined in detail. One hyperdiploid metaphase was observed with 41 chromosomes.

Of the 168 diploid groups containing 40 chromosomes, 135 had minimal or no overlapping of chromosomes and were examined by two independent observers. In 123 of these metaphases, a definite decision was made as to sex. In 113 of these groups, agreement was reached by the two independent observers without consultation while in ten groups, agreement was reached after consultation and reassessment by both observers. There was some doubt 
regarding sexing of the remaining twelve metaphases and these were excluded from the series.

The 123 groups in which a definite decision was made as to sex were then analysed according to the time of preparation after $\mathrm{HCG}$, and this information is presented in Table 2. Though the number of preparations for each time interval is small, the ratio did not differ from $1: 1$ at any stage.

In order to present the facts clearly, it is necessary to compare a normal diploid metaphase group at the 'chromatid' stage of the first cleavage mitosis (Pl. 1, Fig. 1) with a parthenogenetically induced haploid group (Pl. 1, Fig. 2) at the same stage of metaphase. In the parthenogenetically activated egg, no $\mathrm{Y}$ chromosome is present. Both these metaphase groups are stained with Giemsa directly after air-drying and without any form of pretreatment. Plate 2, Fig. 3 illustrates a haploid metaphase group at the 'chromatid' stage of the first cleavage mitosis stained with Giemsa after the specific pretreatment procedure

Table 2. Numbers of male and female metaphase groups in mice observed at various times after $\mathrm{HCG}$

\begin{tabular}{c|c|c}
\hline $\begin{array}{c}\text { Time after } H C G \\
(\mathrm{hr})\end{array}$ & Male & Female \\
\hline 27 & - & - \\
28 & 1 & 1 \\
$28 \frac{3}{3}$ & 5 & 2 \\
$29 \frac{1}{4}$ & 15 & 14 \\
$29 \frac{3}{4}$ & 9 & 10 \\
$30 \frac{1}{2}$ & 24 & 26 \\
32 & 2 & 5 \\
33 & 5 & 3 \\
34 & 1 & - \\
Total & 62 & 61 \\
\hline
\end{tabular}

described above. Characteristic banding and the slight chromosomal contraction produced is apparent. The group illustrated in Pl. 2, Fig. 3 has been arranged as a karyotype (Pl. 3, Fig. 4) and the chromosomes numbered according to the Standard Karyotype of the mouse (Committee on Standardized Genetic Nomenclature for Mice, 1972). Plate 3, Fig. 5 shows a normal diploid group at early metaphase before chromatid separation stained with Giemsa after the specific pretreatment procedure. This is the karyotype of a normal male mouse, $40 \mathrm{XY}$, and illustrates the characteristic appearance of the Y chromosome.

A further series of twenty well-spread first cleavage metaphases were examined under phase contrast (unstained) and a definite decision made as to sex in all cases. These preparations were stained with Giemsa after barium hydroxide and ' $2 \times$ SSC' pretreatment and were re-examined. In all cases where the group had been sexed as male, the $\mathrm{Y}$ chromosome was morphologically distinguishable from the smallest pair of autosomes. In some cases, it was impossible to distinguish the $\mathrm{X}$ chromosome from one or more of the four longest pairs of autosomes because of the similarity of its banding pattern. 


\section{PLATE 1}

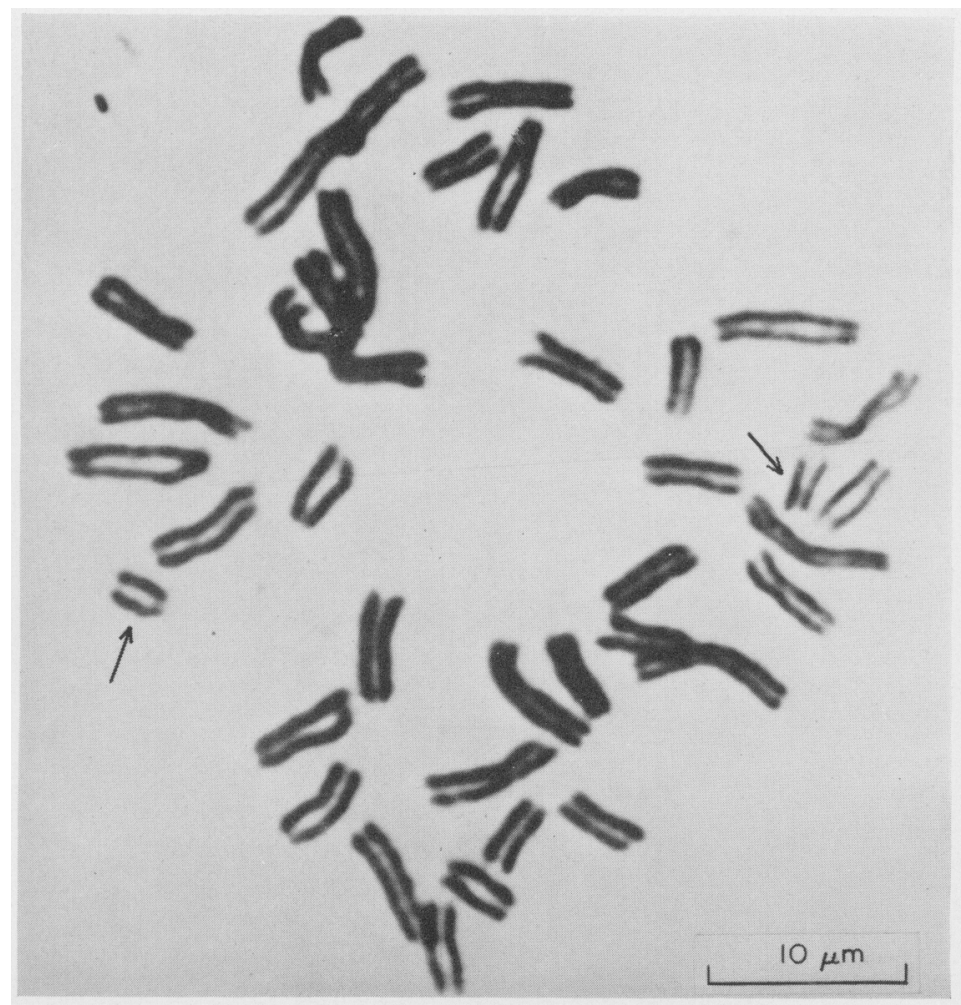

Frg. 1. First clcavage division, diploid metaphase group at the 'chromatid' stage of a mouse. No pretreatment before Giemsa staining. This is a female cell as two small chromosomes are present (arrowed).

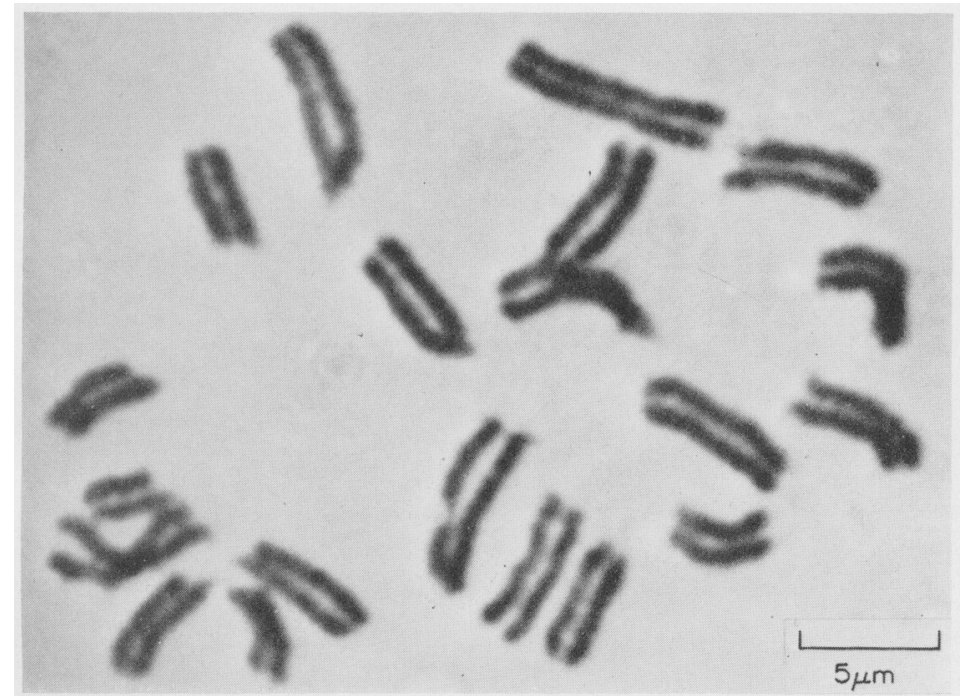

FtG. 2. First cleavage division, haploid metaphase group at the 'chromatid' stage of a mouse oocyte. No pretreatment before Giemsa staining. 
PLATE 2

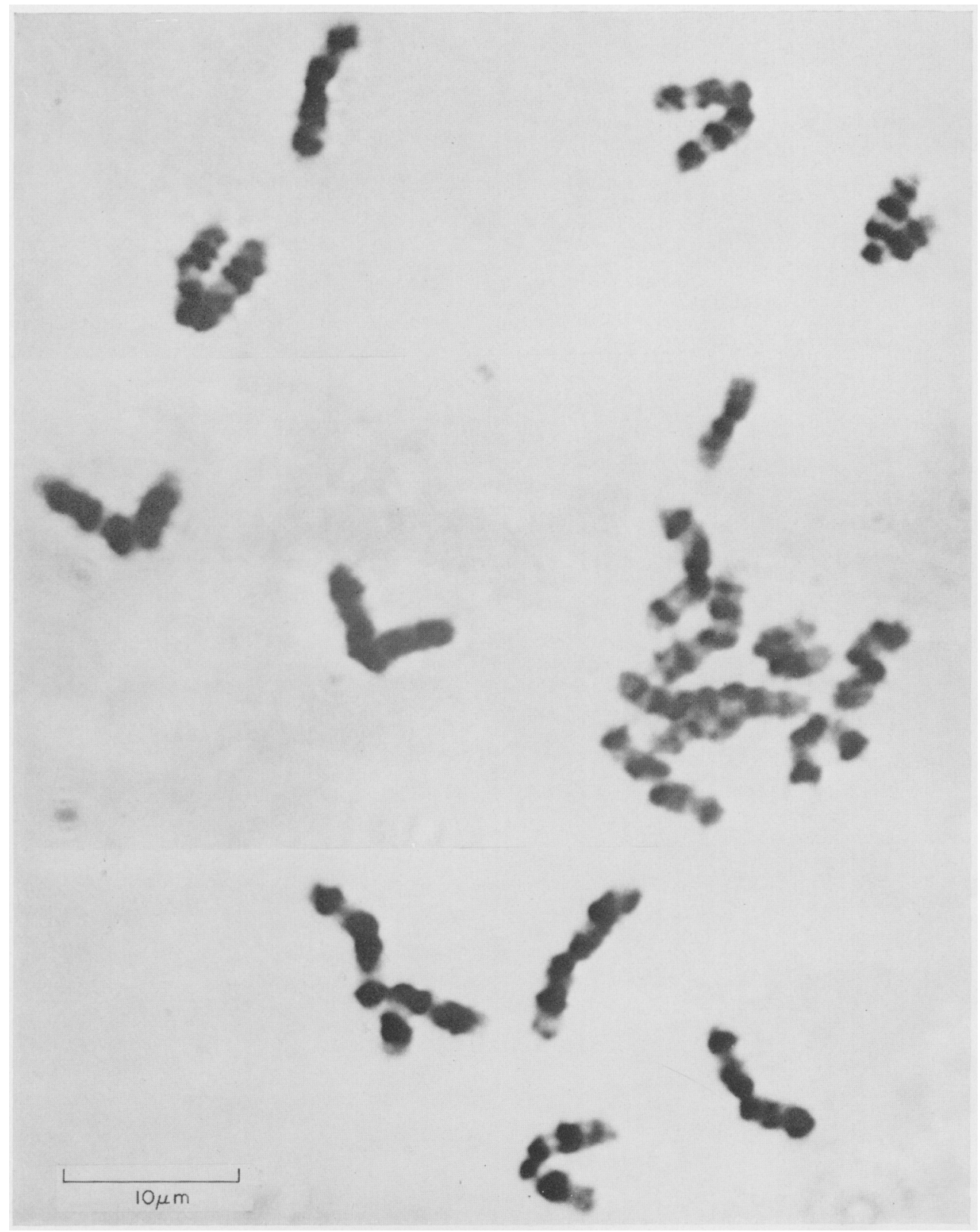

FIg. 3. First cleavage division, haploid metaphase group at the 'chromatid' stage of a mouse oocyte. Barium hydroxide and ' $2 \times \mathbf{S S G}$ ' pretreatment before Giemsa staining, showing chromosome banding. 
PLATE 3

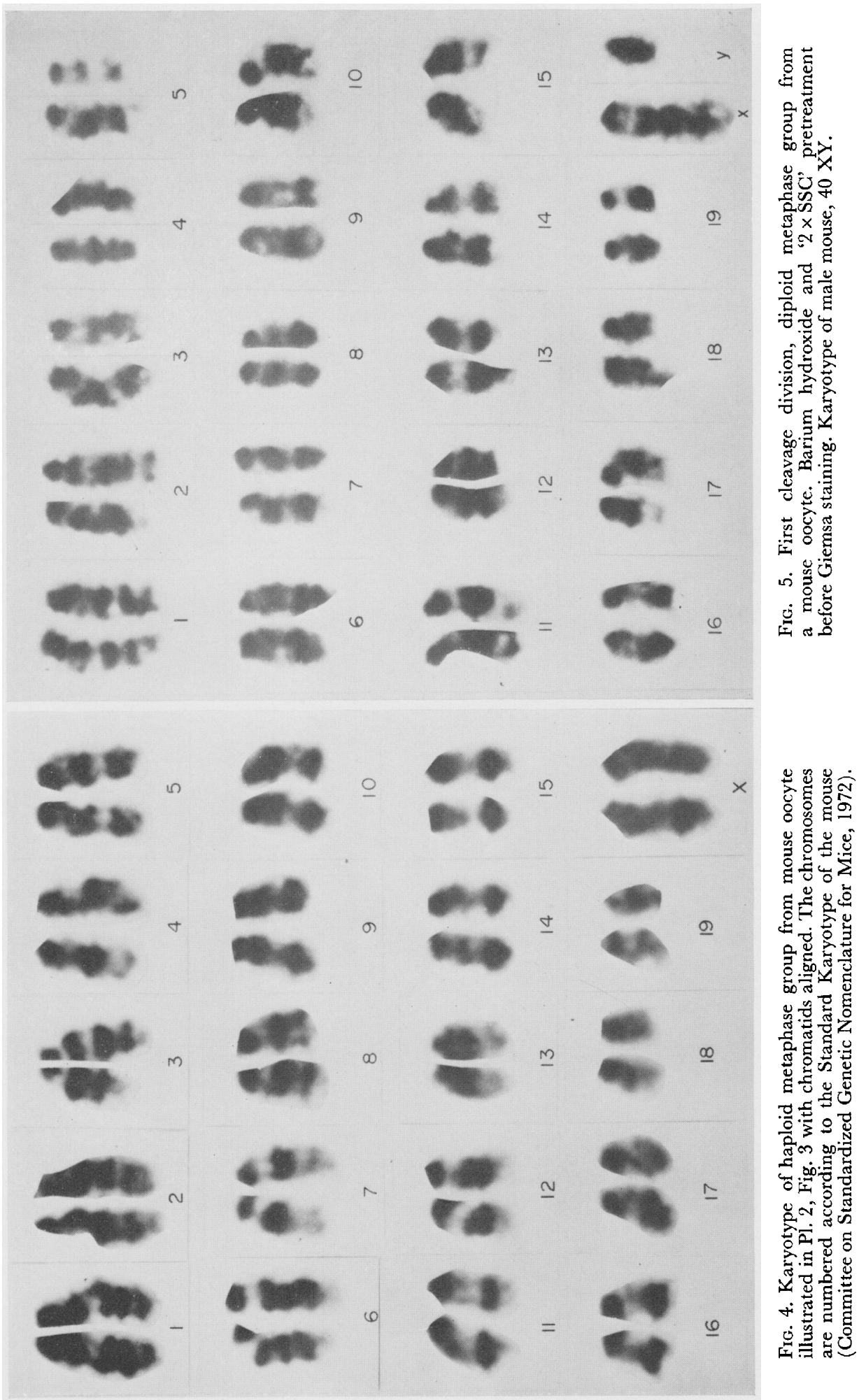




\section{DISCUSSION}

The present investigation has revealed direct evidence on the sex-ratio at conception for the first time in mammals, showing it to be approximately $1: 1$ in the mouse. The earliest previous series of mouse embryos to have been satisfactorily sexed were at the blastocyst stage (Vickers, 1967, 1969a, b) where the ratio of male to female was found to be $1: 1$ in mice of the PDE strain, and a similar ratio was observed in a delayed fertilization group. These results, together with those now reported, suggest there is no sex-selective mortality operating at any stage of gestation from fertilization onwards.

Two methods are available to karyotype the first cleavage mitosis. Because of the considerable difference in length between the chromosomes, the method described by Stich \& Hsu (1960) for somatic tissues is equally applicable to this division, and is possibly easier to evaluate than at later stages. Groups were sexed by this method according to the number of small chromosomes present, whether a pair (female) or three small chromosomes (male). When there were more than three chromosomes in the smallest group, it was necessary to determine whether there was an odd (male) or even (female) number present. This method is open to the criticism that the $\mathrm{Y}$ chromosome cannot be distinguished morphologically with certainty in many groups where the three smallest chromosomes are present, and that the $\mathrm{X}$ chromosomes cannot be distinguished at all by this means.

The staining procedure described in this paper was developed to counter these arguments and to distinguish the homologous pairs of autosomes from the sex chromosomes. To distinguish the male karyotype with certainty given a group of 40 chromosomes, it is sufficient to demonstrate 19 paired chromosomes with an additional unpaired large and small chromosome. For the purpose of sexing groups, it does not matter whether the autosomes have a similar banding pattern to adult-type chromosomes or not.

The banding pattern observed in first cleavage metaphases closely resembles the ideogram of the mouse mitotic chromosome complement illustrated in the Standard Karyotype of the mouse (Committee on Standardized Genetic Nomenclature for Mice, 1972). At the first cleavage metaphase, the pattern is more likely to represent the 'true' picture of events, as fewer artefacts of chromosomal contraction have been introduced (Sasaki, 1961).

Mitotic figures were sexed by the criteria of Stich \& Hsu (1960) under phase contrast (unstained), then checked by the more specific staining method, and a very high concordance obtained. As this was the case, the previous series of metaphases (Table 1) which had been sexed by the same method were considered a valid assessment of the sex-ratio at the first cleavage division.

\section{ACKNOWLEDGMENTS}

I would like to thank Dr R. L. Gardner and Dr P. Barlow for advice and discussion, Mrs J. Corrigan for independently analysing the metaphase groups, Miss J. Baff for photographic assistance, and Professor C. R. Austin for his interest and criticism of the manuscript. The work was supported by a grant from the Ford Foundation. The author is a recipient of an M.R.C. Junior Research Fellowship. 
Buckiand, R. A., Evans, H. J. \& Sumner, A. T. (1971) Identifying mouse chromosomes with the ASG technique. Expl Cell Res. 69, 231.

Committee on Standardized Genetic Nomenclature for Mige (1972) Standard karyotype of the mouse, Mus musculus. F. Hered. 63, 69.

Donamue, R. P. (1972a) Cytogenetic analysis of the first cleavage division in mouse embryos. Proc. natn. Acad. Sci. U.S.A. 69, 74.

DonaHuE, R. P. (1972b) Fertilization of the mouse oocyte: sequence and timing of nuclear progression to the two cell stage. F. exp. Zool. 180, 305 .

Ford, E. H. R. \& Woollam, D. H. M. (1963) A colchicine, hypotonic citrate, air drying sequence for foetal mammalian chromosomes. Stain Technol. 38, 271.

FRANCKE, U. \& NESBITT, M. (1971) Identification of the mouse chromosomes by quinacrine mustard staining. Cytogenetics, 10, 356.

Kaufman, M. H. (1973a) Timing of the first cleavage division of the mouse and the duration of its component stages: a study of living and fixed eggs. F. Cell Sci. 12, 799.

KaUfMan, M. H. (1973b) Timing of the first cleavage division of haploid mouse eggs, and the duration of its component stages. F. Cell Sci. (in press).

MacDowell, E. C. \& LoRd, E. M. (1925) Data on the primary sex-ratio in the mouse. Anat. Rec. 31, 143.

MCGAUGHEY, R. W. \& CHANG, M. G. (1969) Inhibition of fertilization and production of heteroploidy in eggs of mice treated with colchicine. J. exp. Zool. 171, 465.

McGaughey, R. W. \& Chang, M. C. (1971) Chromosomes at prometaphase and metaphase of the first cleavage in mouse and hamster eggs. F. exp. Zool. 177, 31.

Miller, O. J., Miller, D. A., Kouri, R. E., Allderdice, P. W., Dev, V. G., Grewal, M. S. \& Hutron, J. J. (1971) Identification of the mouse karyotype by quinacrine fluorescence and tentative assignment of seven linkage groups. Proc. natn. Acad. Sci. U.S.A. 68, 1530.

SASAKI, M. (1961) Observations on the modification in size and shape of chromosomes due to technical procedure. Chromosoma, 11, 514.

Schnedi, W. (1971) The karyotype of the mouse. Chromosoma, 35, 111.

Sтісн, H. F. \& Hsu, T. C. (1960) Gytological identification of male and female somatic cells in the mouse. Expl Cell Res. 20, 248.

TARKowski, A. K. (1966) An air-drying method for chromosome preparations from mouse eggs. Cytogenetics, 5, 394.

VICKERs, A. D. (1967) A direct measurement of the sex-ratio in mouse blastocysts. F. Reprod. Fert. 13, 375.

Vickers, A. D. (1969a) Delayed fertilization and the prenatal sex-ratio of the mouse. F. Reprod. Fert. $20,63$.

Vickers, A. D. (1969b) Delayed fertilization and chromosomal anomalies in mouse embryos. F. Reprod. Fert. 20,69. 